beneficiário deixou de comunicar. Impõe-se, pelas circunstâncias láticas e pela interpretação do contrato, o ressarcimento das despesas efeluadas. Incluindo-se, ai, despesa com tomografia computadorizada.

24 Veja protesto do Deputado José Pinotti na audiência pública de $18 / 04 / 96$, CFT N.0244/96, p. 23 existentes Pode-se provar as doenças doenças premulher guro-saúde há dois de mama, que assinou um seanos, porque é verdade. $O$ câncer anos antes de aparecer como um tumor de leva dez timetros. Portanto, esse plano é um absurdo."

25 Veja o regime desta cláusula bastante comum, nosso artigo na Revista AJURIS 64, p. 64ss.

26 Veja decisão do TJSP citando a jurisprudência acentada, in: RT 723/346ss.

27 Ap. Civ. 592088512, $3^{\text {a }}$ C.Civ., 30-9-92, Rel. Des. Jão Loureiro Ferreira e Ap. Civ, 5 9201077, 2a Câm. Civel, Relator Des. Ivo Gabriel da Cunha, não publicadas.
28 Assim decisão do TJSP de 25.5.95, Ap. 263.362-2/ 8, 10.C, Rel. Des. Borelli Machado, reproduzida in: RT 721/127, com a seguinte ementa: "A figura da abusiva a fixação do periodo de carência para pequenas cirurgias e, não tendo o convênio de assistência médico-hospitalar produzido prova algum que justifficasse o prazo tão alargado, aplica-se o art. 51, I do C.D.C.

29 Sobre a eventual responsabilidade solidária veja nosso artigo in AJURIS $64 \mathrm{e} 0$ artigo de França, Geraldo Veloso de, $O$ Codigo do Consumidor e exercicio da medicina, in: Revista Direito do Consumidor, vol. 13, p. 56ss.

Veja art. 50 do Projeto de Lei no $4.425 / 94$, o qual exclui as doenças preexistentes à assinatura do nação artificial (IV) tran esteticos (III e V), insemitos odontoló $(\mathrm{X})$, as calamidades e as epidenas (inciso XII). Veja Parágrafo único do art. $5^{\circ}$ do Projeto de Lei n
$4.425 / 94$.

\title{
Sobre la Existencia de Una Familia Jurídica Latinoamericana
}

\author{
DiEgo P. FERNANDEZ ARROYO \\ Universidad Complutense de Madrid \\ Professor correspondente e co-orientador do \\ Grupo de Pesquisas do Depto ${ }^{\circ}$ de Direito Público e Filosofia do Direito. \\ Coordenado pela Prof ${ }^{\sharp}$ Claudia Lima Marques, UFRGS
}

\section{SUMARIO}

I - Introducción; II - Ubicación del "Derecho latinoamericano" em las Clasificaciones Tradicionales del Derecho Comparado: 1. El "Derecho Latinoamericano" Como Rama Diferenciada de la Familia Juridica Romano-Germánica; 2. La "Originalidad" del Derecho Latinoamericano; $\mathrm{III}$ - Revision de la Cuestión a la Luz de Una Concepción Funcional del Metodo Comparativo: 1. Perspectiva Funcional de la Actuacion del Metodo Comparativo; 2. La parativo Funcional, Clasificación de Familias Junídicas y "Derecho Latinoamericano": IV - A Modo de Conclusiones.

\section{I - INTRODUCCION}

1. En otras oportunidades, al ocuparnos de un tema tan concreto como es la codificación del Derecho internacional privado en América Latina, hemos hecho ya alusión a la cuestión que ahora tratamos'. Alli, los respectivos desarrollos tenian una finalidad evidentemente explicativa aunque no por ello meramente referencial. Particularmente parecia importante desentrañar si los mecanismos de producción juridica relativos a un sector especifico y las relaciones reciprocas entre ellos, se veian de algún modo condicionados o diferenciados por el hecho de operarse dentro de una familia juridica determinada. Desde esa perspectiva pudimos concluir que la idea central de la gran mayoria de los desarrollos teóricos comparativos, que pasaba por la reducción de los ordenamientos juridicos a determinados tipos (familias juridicas), choca contra los elementos particulares que presentan las distintas ramas del Derecho. Entre otras razones, porque cabe aceptar con alcance general que cada rama - dentro de un mismo ordenamiento - esta marcada por principios e influencias diferentes y que, por lo tan- to, resulta prácticamente imposible acceder a una clasificación global plenamente satisfacto$\mathrm{ria}^{2}$.

No obstante ello, sin dejar de tener en cuenta esas conclusiones y sigiendo amables sugerencias, hemos de detenernos en el presente trabajo precisamente en la solvencia de los planteamientos referidos a la existencia de una familia juridica latinoamericana. A tal fin consideramos pertinente seguir el hilo de algunos in entos clasificadores relevantes, tomando en cuenta la variación fundamental producida en la actuación del método compartivo desde los postulados más clásicos hasta su modernizaciôn "funcional"; es decir, distinguiendo dos corrientes básicas según el caráter de los elementos que se utilizan y la aptitud para captar la globalidad del ordenamiento juridico de cada Estado ${ }^{3}$. Podrá intuirse rápidamente que a partir del tratamiento de la cuestión en el ámbito concreto definido, se acercarán argumentos más generales para una compresión de la utilidad del método comparativo y de la trancendencia de la clasificación de los ordenamientos jurídicos en familias. 


\section{II - UBICACION DEL "DERECHO \\ LATINOAMERICANO" EN LAS \\ CLASIFICACIONES TRADICIONALES DEL \\ DERECHO COMPARADO}

1. El "Derecho Latinoamericano" Como Rama Diferenciada de la Familia Jurídica Romano-Germánica

2. La calificación de tradicionales con que hacemos referencia a determinadas clasificaciones alude al hecho de su repetición o sus impercetibles modificaciones en las propuestas de autores de diferentes épocas. El elemento común a todas ellas es el basamento, bien que en mayor o menor medida, en criterios que podriamos considerar estáticos, por mor de su rigidez y su falta de aprehensión de la globalidad del fenómeno que se pretende abarcar. Asi, se encuentran clasificaciones cimentadas sobre parámetros tales como la raza, el pasado común, la ideologia dominante, la religión, el carácter predominante de una fuente del Derecho o el grado
de influencia del Derecho romano u otras forde influencia del Derecho romano u otras for-
mulaciones juridicas. La presencia del elemento común subrayado no impide ver diferencias en la caracterización de los mismos ${ }^{4}$. Pero como nuestro objetivo no consiste aqui en realizar una completa descripción de todas las clasificaciones ni su critica, sino de descubrir la plaza que coupa en ellas el Derech ocupa en ellas el Derecho latinoamericano y sus causas, nos basta con la señalización efectuada. Lo que importa es que los resultados del empleo de estos y otros criterios igualmente generales han sido habitualmente pobres y carentes de utilidad. Sin entrar todavia a la critica que merecen en general los ensayos clasificatorios, es evidente que sólo si se siguen pautas más rigurosas en su confección pueden entrar a plantearse seriamente argumentos en favor y en contra de su solidez y del interés que presen$\tan$.

3. Hay constancia de casi tantas clasificaciones de ordenes juridicos en familias como comparativistas han existido. Sin embargo es factible destacar sólo algunas de ellas haciendo referencia a los criterios tenidos en cuenta para su elaboración, obviando el tedioso y probablemente inútil trámite de confeccionar un catálogo exhaustivo y sin ajustarse necesariamente a una secuencia cronológica. Esto significa que pueden señalarse unas pocas clasificaciones, suficientemente representativas, sobre la base de los distintos argumentos escogidos por sus autores para determinar la adscripción de cada ordenamiento a tal o cual familia juridica. Es a partir de ahi que el esfuerzo se dirige a razonar a presencia del "Derecho latinoamericano" - 0 de los ordenamientos que determinado sector de dichas clasificaciones: el constituido, según las diferentes concepciones, por la familia romano-germánica, (europeo) continental, del Derecho civil o, con mayor amplitud, occidental.

En effecto, y como ha quedado indicado, los criterios rígidos de los que hablámos nos llevan por un camino que desemboca siempre en formpre en forpulaciones un tanto forzadas. Clertamente, algunos de aquéllos tienen más relación que otros con la configuración de las familias, en razón de atender a un elemento de contenido juridico; de este modo, el peso que ha ejercido el Derecho ento equis podria tal vez parecer mas idoneo a los fines propuestos que la raza de los habitantes del Estado donde está vigente. Sen embargo, todos brindan conclusiones insastifactorias. Son incompletas, visiblemente incorrectas, 0 ambas cosas. A esto hay que añadir que en la elección de uno u otro criterio subyacen las convicciones espirituales del comparativista en tanto animal politico, tiñendo de colores subjetivos los resuldos de su tarea.

4. La raza es el argumento utilizado en algunas de las primeras clasificaciones. En éstas, los órdenes juridicos de los Estados de América latina se incluyen explícita o implícitamente dentro de la familia correspondiente a la raza "romana" o "latina". La inadecuación del criterio racial a la tarea descriptiva intentada por sus autores salta a la vista al observar las otras razas consideradas como significativas. Incluso, no simpre lo que se menciona como raza lo es en sentido estricto, ni se tiene en cuenta que éstas no se mantienen en estado puro y que su en el mundo suele no coincidir con la división politica y, por tanto con las fronteras juridicas ${ }^{5}$. Asi, aparecen en esos cuadros junto a la supuesta familia romana o latina, los derechos de los pueblos anglosajón, germánico, eslavo y musulmán ${ }^{6}$, o teutón, hindú y mahome$\operatorname{tano}^{7}$ o inglés, musulmán, hindú y chino ${ }^{8}$. También se ha ensayado una división entre los pue- blos de raza aria o indoeuropea, semita, mongólica y un cuarto grupo destinado a recoger los pueblos "bárbaros", esencialmente costumbristas. En ella, los pueblos de Latinoamérica se colocan en el último sector (derechos de los pueblos "indigenas de América") y en el primero, dentro de los derechos grecolatinos, que comparten una llamativa clasificación con los derechos hindú, iraní, celta, gérmanico, anglosajón y eslavo ${ }^{9}$.

5. Tan poco riguroso como el criterio racial se revela aquel que pone el acento en la actitud del ordenamiento considerado respecto de la religión ${ }^{10}$. Dentro de tal argumentación se destaca una familia occidental que, pese a no reconocer carácter de fuente del Derecho a las normas religiosas, presenta un espiritu religioso notoriamente influenciado por el cristianismo. Las otras familias identificadas en esta clasificación son la soviética, caracterizada por su sencacion son la soviética, caracterizada por su sen-
timiento "antirreligioso", y la de los derechos timiento "antirreligioso", y la de los derechos
estrictamente religiosos, donde se ubican el caestrictamente religiosos, donde se

La primera, que también se distingue por Laber establecido una organización social y politica de base cap e compone de cinco ramas: la angloamericana, la romanista - dominada por el modelo codificador francés - , una particular rama "de Derecho romano" que no siguió este modelo - donde se incluye a Cataluña y a Sudáfrica -, la escandinava - que no recibió ni el Derecho romano ni la codificación a la francesa - y, finalmente, la latinoamericana, que se excluye de la romanista porque además de la mayoritaria influencia francesa, sufre la impronta de los derechos español, norteamericano, alemán e italiano. Como puede colegirse, la división en ramas se realiza siguiendo un criterio que no guarda ninguna relación con el de la clasificación general, lo cual le quita todavía más sustento. Precisamente es la falta de fuerza y claridad de la argumentación lo que impide colocarla en el subepigrafe reservado a las clasificaciones que reservan un sitio al Derecho latinoamericano en razón de alguna nota de originalidad.

6. Más curioso aún es el intento de agrupar los ordenamientos jurídicos del mundo tomando en cuenta junto a otros elementos la lengua que se habla en los paises donde están vigentes $^{12}$. En efecto, el autor del mismo, después de considerar que existe una rama autónoma dentro de la familia jurídica latina que reúne a los derechos de España, Portugal, Iberoamérica, Puerto Rico y Filipinas, realiza una rara clasificación que ubica a la misma dentro de la familia ("áreas") de ordenamientos juridicos que presentan una unidad lingüistica. En ésta ocupa una plaza junto a los derechos angloamericano alemán y escandinavo. Las matizaciones que caben hacer a este engendro se convierten en asombro al contemplar que las otras dos familias que conforman el cuadro son la que agrupa a los ordenamientos ejemplares - en la cual se encuentran los derechos francés y soviético - y la de los derechos trascendentes - hindú, musulmán y chino no trascendente -13 .

7. Por su parte, en las distintas clasificacioideológica muy clara, aunque el autor se esfuerza por mostrar una apreciación más amplia y compleja. Señaladamente, pone el acento sobre dos consideraciones: una técnica, relativa a las posibilidades que asisten a un jurista formado en el ámbito de vigencia de un ordenamiento para desenvolverse con solvencia en los otros, y otra ideológica, dirigida al tipo de sociedad que se pretende realizar. Sin lugar a dudas, ésta determina a aquélla y se convierte en la piedra angular de todas los intentos de David ${ }^{14}$. Sin enbargo, al incluir en sus obras algunas disquisiciones acerca de la necesidad de no limitar el análisis comparativo sólo a ciertos aspectos de los ordenamientos en cuestión, recorrió una temática que seria desarrollada más tarde tambien por otros autores y alli radica su mayor mérito.

Su primera formulación ${ }^{15}$ dividia el horizonte juridido en cinco grandes familias: occidental, soviética, musulmana, hindú y china. En tal construccion, la occidental descansa sobre dos derechos representativos: el francés (al que pertenecen los "Derechos de la América latina") $\mathrm{y}$ el common law. Ambos tienen en común los principios politicos del liberalismo, la estructura económica capitalista y la moral cristiana, además de un sentimiento caracteristico respecto al rol que debe cumplir el Derecho en la sociedad ${ }^{16}$. Como hemos indicado, la concepción pergenada por este autor varia, pasando a componerse por tres familias: romano-germánica, common law y socialista ${ }^{7}$. En un cuarto grupo como si del bosillo de un payaso se tratara, mete 
todo lo que queda fuera de aquéllas, llamándolos "sistemas filosóficos o religiosos", reconociendo que no constituyen familias propiamente dichas $^{18}$. Lógicamente, los derechos latinoamericanos se ubican dentro de la familia romanogermánica, bautizada asi para poner de relieve, unto al origen romano, la esencial aportación de la ciencia ${ }^{19}$

8. Justamente, la ya señalada influencia del Derecho romano ha servido también como parámetro clasificador ${ }^{20}$. Con ese argumento, se ha agrupado a los ordenamientos juridicos según hayan sufrido una fuerte influencia del Derecho romano, niguna o una mixtura de influencias romanas y germánicas. En el primer sector se encuentran los derechos rumano, italiano, español, portugués y griego, en el segundo Inglaterra, Rusia y los países escandinavos, y
en el tercero Francia, Alemania y Suiza. Al ser en el tercero Francia, Alemania y Suiza. Al ser
una clasificación limitada a Europa, no se inuna clasificación limitada a Europa, no se inricano, aunque posiblemente pudiera colocár sela a caballo entre la primera y la tercera ${ }^{21}$

9. Emparentada con la caracterización anterior, encontramos otra clasificación que toma en consideración entre otros elementos datos históricos, agrupando de esta manera los ordenamientos en los cuales se reconoce un pasado común ${ }^{22}$. Las siete familias localizadas desde tal perspectiva son: la francesa, la inglesa, la germánica, la escandinava, la soviética, la islámica y la hindú. Dentro de la primera, junto a los derechos de España, Portugal, Louisiana y Quebec entre otros, se ubican los derechos de America Latina. Queda claro que el origen común rica Latina. Queda claro que el origen comun ordenamientos ${ }^{23}$, pero tambén es cierto que en caso de existir habrá de imprimir en alguna medida cierto caracter distintivo. De todas maneras, la carencia principal de la clasificación debe buscarse, una ve $z$ más, en su estructura formal y estática, que impide ver hasta qué punto los distintos ordenamientos no se mantienen "puros" dentro de la misma familia.

10. Por último, el peso decisivo de una determinada fuente del Derecho provoca que la condificación 0 , más exactamente, la actitud de cada ordenamiento frente a la misma, se convierta tambén en un parámetro ${ }^{24}$. Con ese punto de partida se agrupan, de un lado, la familia europea continental o romanista y, de otro, la del common law. Es decir que, en un trabajo a la vez simple y poco esclarecedor se enfrentan os ordenamientos codificados a los no codificados. Entre los primeros, donde conviven "codios muy distintos, se encontrarán los latinoagos muy distintos, se encontrarán los latinoamericanos por fuerza de la evidencia, aunque no siempre hayan sido tenidos en cuenta por los autores de este tipo de clasificación ${ }^{25}$

\section{La "Originalidad" del Derecho}

Latinoamericano

11. Sin abandonar un punto de vista más o menos rigido, se ha ensayado justificar la existencia autónoma del Derecho latinoamericano, basándose en ciertos aspectos que le confieren originalidad. Dicha tarea no implica, evidentemente, negar la adscripción al tronco común romano-germánico, sino que intenta, con diferentes alcances, demostrar los perfiles propios que ha ido adquiriendo aquél en su evolución (nomogenetics), distinguiéndose asi de la rama latina o francesa. Normalmente, la idea se ha limitado a agrupar los ordenamientos de la región, sobre todo desde una perspectiva latinoamericana. Sin embargo, en algunas construcciones desarrolladas en España, la comprensión de dicha familia abarca al ordenamiento de este pais, haciéndola asi ibérica y americana. Tal extremo no puede sorprender si se tienen en cuenta los lazos históricos y la importancia que se le han otorgado desde los campos más variados. Resulta de particular relevancia el efecto que han causado los trabajos españoles sobre no pocos estudiosos de otros paises europeos en particular, de Italia - que han realizado importantes trabajos de investigación sobre el Derecho de los paises latinoamericanos. En todos ellos, sin embargo, el reconocimiento de una cierta sustantividad a éste se opera sobre la base de demostrar la pervivencia del Derecho romano y la relativa impermeabilidad a las influencias de otras concepciones jurídicas ${ }^{26}$

Inevitablemente, el centro de atracción de gran parte de las distintas teorias esbozadas en torno a este punto, está constitutuido por los códigos civiles, que comenzaron a promulgarse en América Latina a mediados del siglo XIX ${ }^{27}$, con algún antecedente más o menos aislado. La transcendencia que alcanzaron los códigos en el continente americano justifica en cierto sen- tido esta tendencia. No obstante, no dejamos de reconocer que la sola atención a los mismo especialmente en trabajos no suficientemente documentados - puede llevar a una falta de correspondencia entre el anälisis y la realidad juridica de nuestros dias ${ }^{28}$

12. Desde muy temprano en la historia de los ensayos de clasificación en familias jurídicas, autores latinoamericanos inscriben su nombre en la corriente que nos ocupa. Ya a finales del siglo XIX C. Bevilaqua afirma que los ordenamientos latinoamericanos no resultan clasificables ateniéndose sólo a la influencia de los Derechos romano o bärbaro. Para ello se basa en la consideración de dos elementos que caracterizan a aquéllos, otorgándoles un tinte especial: la democracia y la libertad sobre las cupecial: la democracia y la libertad sobre las cu-
ales se edifican ${ }^{29}$. Sin escatimar el reconocimiales se edifican ${ }^{29}$. Sin escatimar el reconocimiento a la cualidad de labor pionera que la obra
detenta, se impone alguna observación. Además de las criticas dirigidas a la falta de demonstración de las notas distintivas y del hecho diferencial respecto a otros ordenamientos del mun$\mathrm{do}^{30}$, parece factible impugnar la patente falta de correspondencia entre la clasificación tomade correspondencia entre la clasificación toma-
da como referencia y los criterios utilizados en da como referencia y los criterios utilizados en la diferenciación. Es decir, no se aprecia claramente cómo los argumentos empleados llevan a lia latinoamericana, dentro de una clasificación basada en la descendencia de determinados ordenamientos madres.

Dentro de la misma linea, pero haciéndola ganar en coherencia, se ubica una concepción que sólo toma en cuenta la filiación jurídica, midiéndola de acuerdo con la influencia especifica de los elementos que se consideran caracteristicos de cada ordenamiento ${ }^{31}$. de este modo se obtienen cuatro familias: consuetudinariabárbara (incluye los Derechos inglés y escandinavos), bárbaro-romana (constituida por los de Francia, Alemania y Austria), bárbaro-romanocanónica (Espana y Portugall) y romano-canónico-democrática (donde confluyen Rusia, Suiza y América latina). Como puede observarse, el elemento "democrático" que distingue a la última familia - proveniente de la clasificación anterior - provoca una originalidad discutible y no suficientemente demostrada, además de compartida. Sin embargo, más importancia que ese elemento demustra el acento puesto en la falta de influencia bárbara al otro lado del océa-

13. No deja de ser sorprendente que, sin escapar totalmente de los criterios estáticos, se hayan brindado varios y buenos argumentos al hecho diferencial del Derecho latinoamericano en un trabajo destinado a demostrar la indisolubilidad del vinculo existente entre éste y el Derecho europeo, en especial el francés 32 . La falta de precisión que se advierte en la explicación de algunos elementos tomados en consideración, no resta méritos a un estudio que presente, aunque timidamente, dos cualidades sumamente positivas: la utilización algo desordenada de una pluralidad de criterios, juridicos y extrajuridicos ${ }^{33}$, que constituye la primera aplicacion en este ambito concreto de un germinal método comparativo funcional, y la aproximacion mesocomparativa en el análisis.

En un plano general, el citado trabajo comienza estableciendo que mediante una "concepción realista, sociologica, del derecho", se constata entre los paises de Europa y de América atina varios caracteres comunes (lengua, tradición, creencia e ideal) y diferencias esenciales (geografia, economia, estructura social y raza). obviando aqui una discusión acerca del alcance de cada uno de estos elementos y de su compaginación ${ }^{34}$, los señalados en último término brindan una pincelada básica de originalidad al Derecho latinoamericano. Si se pasa a la mesocomparacion, que el autor realiza en dos niveles, se infiere otro tanto; de un lado, es original el modo de recibir el Derecho público anglosajón (concretamente, norteamericano) ${ }^{35} \mathrm{y}$ hacerlo convivir con Derecho privado de origen europeo continental, y, de otro, también lo es la mixtura que se produce entre las distintas ramas de este: un Derecho civil alineado con pero con elementos españoles y portugueses, un Derecho procesal civil dominado por estos últimos y un Derecho mercantil influenciado notablemente por el Derecho italiano ${ }^{36}$. Igual resultado se obtiene de la observación de las fuentes del Derecho y los modelos recibidos. Asi, en la egislación y en su técnica se vislumbra la impronta alemana; en el excesivo academicismo de las obras juridicas, el autor intuye el parentesco con la doctrina italiana; la jurisprudencia, por su parte, abreva en las fuentes de los tribunales franceses. Finalmente, la originalidad 
en la labor codificadora americana constituye e elemento más formal del análisis y su punto de llegada.

Ahora bien, el dato sorprendente al que haciamos referencia estriba en que después de esta quintuple argumentación, R. David concluye con la tesis que se habia fijado a priori, la unida del Derecho romano-germánico incluyendo a los ordenamientos latinoamericanos, reduciendo todo a una justificación basada en "las condiciones diferentes de desarrollo y de existencia de los paises de Europa y de América" ${ }^{37}$. La originalidad de determinados Ordenamientos no es susceptible de mirarse como un sintoma progresista o reaccionario, como pretende el insigne autor, mucho menos cuando se acaba de demostrar que se trata de una realidad objetiva objetivable Muy a su pesar R. David inicio un camino que otros han profundizado desde otras perspectivas, sin que esto signifique que se comparten sus criterios ni que se dé un alcance desmedido a esa constatación

14. En las señaladas tesis españolas, el denominador común se encuentra en la innegable influencia del Derecho ibérico - sobre todo, his pano - sobre la configuración de los ordenamientos del Nuevo Mundo. En ellas, la sustantivi dad que se reconoce al Derecho latinoamericano redunda en una concreta diferenciación respecto de las otras ramas de la familia romanogermánica. Con el antecedente de las parca referencias de $F$ de Solá Cañizares y $J$. Castan Tobeñas, es J. Ma Castán Vazuez quien desaTolla con mas rolla con más profundidad una investigación minuciosamente documentada en este sentido ${ }^{38}$ Los criterios empleados por este autor se centran en los elementos históricos y culturale comunes y en los datos tangibles de la influen cia juridica espanola. Com ellos desentraña "fondo común" de los ordenamientos latinoamericanos, constituido a partir de las siguientes pautas: el transplante del Derecho castellano América, el envio de libros juridicos a las Indi$a^{39}$, la obra de las Audiencias, las codificaciones americanas, y la práctica juridica común en los paises americanos.

Deben ponerse de relieve los dos caracteres centrales de la teoria. Por una parte aparece limitación material de la familia asi concebida al Derecho privado ${ }^{40}$; a su lado, la presencia en ella del Derecho privado espanol La base historica y cultural es innegable a fuer de evidente pero el dato juridico precisa un mayor esfuerzo de comprobación, y esa es la tarea en la que ha brillado su autor. El grado de espontaneidad que se aprecia en la primera queda condicionado por los intereses estatales manifestados sobre el segund $0^{41}$, y el nivel de exigencia se eleva notablemente. Visto desde otra perspectiva, traducir juridicamente la señalada evidencia no es un trabajo simple, exento de complicaciones ${ }^{42}$. Sin disminuir un ápice los méritos de la teoria, parece deseable un reforzamiento del análisis de los elementos juridicos actuales, en particular de las modernas influencias y de la práctica juridica para arribar eventualmente a una justcompleta y dinámica de la existencia de $\tan$ mentada familia

15. La corriente romanista, por ultimo, ha partido de los datos anteriores para demostra la pervivencia del Derecho romano en los ordenamientos latino-americanos ${ }^{43}$. El denominador común de las diversas postulaciones de esta corriente lo constituye el particular realce del dato histórico-juridico y, en su aspecto más formal, la atención preferente dada a los códigos ${ }^{44}$ De esta manera, el análisis se produce en general con criterios estáticos ${ }^{45}$, tendiendo a perder de vista la configuración tanto de los elementos extrajurídicos cuanto de la puesta en práctica de los juridicos. Sin embar entras algunos autores concluyen con el reconocimiento de una autonomía más o menos limitada del "sistema latinoamericano" 46 , otros pretenden una homologación con los ordenamientos europeos, basada en el origen común ${ }^{47}$ Dos aspectos de esta teoria merecen subrayarse especialmente. De un lado, la preocupación de juristas europeos no españoles sobre estas cuestiones, sobre todo por el hecho de la dificul tad de ver en los ordenamientos latinoamericanos algo distinto de lo que se observa en sus pares europeos continentales ${ }^{48}$. De otro, es preciso no olvidar aunque se comulgue con estos no (y de buen (y de buena parte del francés) en América, se operó a través de España ${ }^{49}$
III - REVISION DE LA CUESTION A LA LUZ

DE UNA CONCEPCION FUNCIONAL DEL

METODO COMPARATIVO

1. Perspectiva Funcional de la Actuación del Método Comparativo

16. El carácter incompleto y algunas veces inexacto que se desprende de las formulaciones concebidas exclusiva o prioritariamente a partir de elementos rigidos, desbroza el camino por el cual se desarrollan ideas que exploran la necesidad y la forma de pergeñar una modificacion del paradigma generalmente aceptado en actuación del método comparativo. De igual modo que en la estructuración del panorama juridico mundial en famílias consideramos que dicha rigidez se concreta en la utilización más 0 menos aislada de los criterios aue señaláramos en otro tipo de estudios comparativos se manifiesta en la atención otorgada a las normas jurdicas generales, a la legislación, como objeto primordial o único de los mismos. Es frente esta actitud generalizada que aquéllas ideas cobran fuerza, dando lugar a un método que, con variantes, permite una aprehensión global y realista de los ordenamientos considerados.

$\mathrm{Ni}$ que decir tiene que el cambio asi operado reviste una importancia singular, aunque tal ve sea un poco exagerado hablr de una revolució cientifica ${ }^{50}$. Aqui no se asite a un supuesto de modificación vertiginosa, mucho menos sorpresiva, de la situación anterior, ni se descartan los instrumentos que en el pasado servian para realizar esta concreta actividad. En efecto: no puede haber sorpresa cuando ya en el XIX se ponia de relieve la necesidad de apreciar la complejidad ofrecida por todos los elementos que $s$ relacionan con el Derecho en su interacción social $^{51} ; \mathrm{y}$ no se produce una ruptura histórica con los criterios tenidos en cuenta en otras época sino que, en lugar de considerarlos individualmente, se combinan, se aplican dinámicamente y se pone el acento en los caracteres activos, en los que mejor determinan el perfil de cualquier ordenamiento, sistema, institución o fenómen juridico.

El término "funcional" aplicado al método comparativo, entonces, se comprende aqui como una actividad plural, multiforme, basada en el análisis de todos cuantos elementos se revelan como indicadores distintivos del Derecho. Pero esta tarea no recae exclusivamente sobre la traducción positiva de éste, sino que se realiza observando también su eficacia social, esto es, sin perder de vista el verdadero impacto que las normas juridicas ejercen sobre las soluciones concretas $^{52}$. Más que de una reacción contra las actitudes excesivamente formalistas 0 positivistas cabe hablar de una evolución a partir de éstas. El paso del análisis estructural del Derecho a una actividad tendente a desentranar el rol que desempeña en la sociedad ha sido una constante en los trabajos de los principales teóricos del Derecho especialmente a partir de la década del cincuenta, y en ningún caso supone un abandono del primero ${ }^{53}$. Antes bien, la evolución señalada se va plasmando mediante la configuración dinámica de um permanente camino de ida y vuelta entre estructura y función, que permite la aprehensión global y realista del Derecho que indicáramos. Exactamente lo mismo se produce en el ámbito concreto del empleo del método comparativo ${ }^{54}$.

En este orden de ideas, los conceptos y las categorías elaborados por la ciencia jurídica "tradicional" no tienen por qué entorpecer la producción cientifica explicativa asi concebida ${ }^{55}$ Incluso, si en algün estudio podía percibirse cierta tendencia en este sentido, sus propios autores se han encargado de matizarla y ponerla en sus justos términos ${ }^{56}$. Existen, sí, multitud de estudios comparativos que se mueven en áreas "taxonómicas, descriptivas (y tipicamente dogmáticas) más que explicativas" 57 ; pero hay un largo trayecto de alli a inferir la inutilidad de conceptos y categorias, mucho menos si éstos, bien que con un entendimiento parcialmente subjetivo, vienen a conformar la estructura de la nueva construcción "revolucionaria"58. Una afirmación de tal talante y envergadura expresada por un jurista del mundo anglosajón, equivaldria a la caracterización de este Derecho como "bárbaro" efectuada por uno de la familia romano-germánica. Una y otra aparecen prima facie como un obstáculo para el trabajo comparativo, toda vez que evidencian la falta de comprensión de lo distinto y una cierta incapacidad para penar el Derecho con otros fundamentos ${ }^{59}$.

Muy lejos de nuestro ánimo está la idea de un respeto a ciegas de la tradición jurídica. Lo que aqui se intenta resaltar discurre por otros derroteros y hace referencia a que no es meto- 
dológicamente licito, habiendo entrado ya en los últimos años del siglo, identificar ciencia juridica (romano-germánica) comparada con estudio exclusivo de la legislación, basándose en la supervivencia de la ecuación Derecho $=$ normas juridicas generales ${ }^{60}$, cuando ya hace muchos años que comparativistas y iusfilósofos de esta familia han superado largamente ambos binomios. Con estas armas, convenientemente dinamizadas, intentamos nosotros también desarrollar una tarea esencialmente explicativa, en el convencimiento de que "ésta proporciona una base para la predicción y, consecuentemente, para la toma de decisiones" 61

17. Partiendo de la base de que la utilizacion del método comparativo no puede agotarse en la teoria juridica ni en la legislación, la respuesta a la pregunta ¿qué debe compararse? depende en todo caso del objetivo perseguido e la investigación. Delimitado éste, el empleo de método debe extenderse mucho más, abarcan do la función normativa en general, la aplicación judicial o extrajudicial del Derecho, la interpretacion $y$, con determinados parametros, los pretacion $y$, con criterios imperantes sociolog $\cos$ o filosoficos del Derecho ${ }^{62}$. La relación estrecha entre objeto de la investigación y com prensión del método en cada caso, de un lado, la conveniente amplitud de ésta, de otro, no obstan a la necesidad de tener en cuenta algunas limitaciones que es preciso trazar en el campo de la comparación, limitaciones que pueden analizarse desde dos dimensiones, una referida a las materias a comparar y la otra relacionad con el número de sistemas conectados con la comparación, En términos generales, la primera se articulará sin dejar de merituar la particularidades de la vida social, económica o politica de los ordenamientos en cuestión, que pueden provocar diferentes grados de comparabilidad según las materias implicadas. Si éstas se presentan como susceptibles de comparación ordenadas al fin perseguido, la extension de la otra dimensión queda a discresión del investigador $^{63}$. En este sentido, puede decirse que la labor de quien compara debe guiarse siempre por la finalidad perseguida con la comparacion 64

En la mayoria de los supuestos la restricción del número de ordenamientos elegidos se conf gura como un requisito indispensable a fin de asegurar los resultados que se esperan obtener Esto significa que la tarea de sintesis y la extracción de conclusiones válidas e interesante se ve dificultada o directamente imposibilitada cuando no se opera la limitación ${ }^{65}$. Son excepcionales los supuestos en los cuales es dable, incluso imprescindible, burlar tal frontera metodológica sin correr el riesgo de la pérdida de rigurosidade int ción del método comparativo para la configuración de las distintas familias juridicas - lo que para algunos constituye precisamente el ámbito propio del Derecho comparado, justificando asi su existencia en cuanto ciencia autónoma ${ }^{66}$ - aunque se ha hecho hincapié en la tarea de preparación de proyectos para la unificación del Derecho"

Sin embargo, la finalidad concreta perseguida concidiona la utilidad práctica de cualquier clasificación y, muchas veces, aquélla suele estar emparentada con la unificación. Estas observaciones son aplicables por igual cuando la comparación discurre exclusivamente en pos de crocomparación), cuando hace referencia a lo dad (macrocomparación) y cuando, en definitiva, se plantea acerca de una rama determinada de la ciencia jurídica (mesocomparación). Si bien es cierto que, como se ha señalado, en la realización de cualquier estudio comparativo resulta siempre conveniente tener una visión de conjunto de los ordenamientos implicados, no lo es menos que existen multitud de trabajos que presentan solamente una labor microcomparativa, y que en sendos casos tienen validez las ideas esbozadas.

18. Desde una perspectiva diferente 0 , mejor dicho, complementaria a la hasta ahora descrita, la respuesta a la pregunta ¿qué debe compararse? puede construirse atendiendo no ya las materias 0 a la cantidad de ordenamientos alcanzados por la comparación, sino a la manera en que cada uno de éstos articula sus normas, principios e instituciones para resolver los problemas concretos suscitados en la aplicación del Derecho ${ }^{68}$. Básicamente, se trata de comparar tomando como foco prioritario de ataque, como objetivo primario, las soluciones que se brindan a las cuestiones prácticas en cada uno de los ordenamientos considerados. Es notorio que la actividad propuesta es mucho más factible en una tarea microcomparativa que en un macrocomparativa.

Lo que se busca por este medio es confronta la "funcionalidad" de las reglas juridicas, tenendo en cuenta que muchas veces distintos sistemas y subsistemas dan lugar a situaciones juridicas y resuelven determinados problema sino de forma identica al menos parec utilizando caminos diferentes. Se ha hablado en este sentido, desde una concepción empirica de método comparativo, de "fungibilidad funciona de instituciones estructuralmente diversas (o viceversa)" 69 , caracteristica que no debe perderse de vista si se busca aprehender el Derecho en su faceta dinámica, el Derecho vivo. Precisamente, las similitudes estructurales 0 institucionales sólo se recogen con cierta fidelidad mediante la comparación y es a través de ésta que adquieren relevancia. La observación aislada de un ordenamiento o de una parte de él dificilmente brinde los elementos necesarios para una comprensión total del objeto en estudio ${ }^{70}$, para que alcance rigurosidad, se propugna el seguimiento de una "cadena circular" que abarque a los supuestos de hecho, la norma juridica destinada a regularlos y las decisiones jurisprudenciales - no siempre ajustadas a las disposicione del texto legal -, complementándose con el anàlisis de las condicionantes sociológicas, filosóf cas y politicas, que informan tanto a las nor mas positivas como a las decisiones emanadas mas positivas com

La opción funcional para la comprensión de método comparativo, permite solventar el obstáculo que representa el hecho de que mucha normas diferentes cumplan idéntico o parecido objetivo social ${ }^{72}$. No es demasiado raro encontrar trabajos en los cuales puede apreciarse error en que se suele caer cuando se compara consistente en limitar la tarea al análisis de norma y al sector de la realidad social que ell contempla, sin averiguar la funcionalidad de la misma en la realidad juridica concreta ${ }^{73}$. Es preciso insistir: en toda decisión judicial o administrativa subyacen criterios sociológicos, filosóficos y politicos, y se podria agregar, como estrechamente vinculados a ellos, los de orden histórico (tradición-precedente) y económico. La influencia de todos y cada uno de estos elementos en la construcción de las soluciones mater- ales, vien siendo destacada por un buen número de autores, del mismo modo que su acción sobre la labor legisladora ${ }^{74}$

Quien, como parte de un estudio comparativo de Derecho, desee comprender la regulación juridica de los contratos en un pais sometido a recurrentes procesos inflacionarios y busque las respuestas y los datos sólo en su Código civil y arribar jamás a un resultado satisfactorio, toda ve la situacion economica critica genera medificaciones en el funcionamiento de los textos legales, mediante la acción de la Administración, de los jueces y de los propios particulares. Un estudio que no tuviera en cuenta aspectos como los mencionados, no sería comparativo en el sentido expuesto y, en la mayoria de los casos, careceria de interés ${ }^{75}$. En definitiva, puede afirmar-se que el método comparativo aplicado a la ciencia jurídica estriba en confrontar los supuestos de hecho y las soluciones respectivas ${ }^{76}$ a la luz de los elementos subyacentes relevantes que motivan estas últimas y que informan a los propios ordenamientos juridicos implicados en la comparación.

2. La Búsqueda de los Elementos Esenciales del Ordenamiento Mediante Una

Aproximación Compleja

19. Con base en los argumentos expuestos, se han elaborado teorias concretas que han sido aplicadas en estudios comparativos de distinto alcance. El denominador común de aquéllas estriba precisamente en la búsqueda de una apreciación a la vez general y profunda de los ordenamientos examinados, atendiendo a los elementos juridicos y extrajurídicos que caracterizan tanto su "en si" cuanto su "para si". Hemos indicado que ya en el siglo pasado es dable encontrar algunas manifestaciones del pensamiento juridico tendentes a una concepción metodológica de raigambre funcional para los estudios comparativos, ideas que cobran un auge considerable en la presente centuria en particular después de la Segunda Guerra Mundial. A medida que el análisis funcional del Derecho va ganando adeptos entre los iusfilósofos, comienzan a proliferar tímidas aplicaciones en la esfera comparativa que pronto desembocan en importantes teorias acerca de la instrumentaliza- 
ción del método. Entre ellas se manifesta una tendencia que se ocupa de destacar la investigación sociológica como una parte esencial del
método comparativo y que acaparó una significativa proción de la atención en el VIII Congreso Internacional de Derecho Comparado que tuvo lugar en Pescara en 1970. Dicha tendencia busca acentuar, en la linea de lo que veniamos exponendo, la importancia del "living law" contrastándolo con el "law in the books" 77 .

Ya en 1961, R. David hacia alusión a los juristas que ponen especial atención en los aspectos más funcionales del Derecho, indicando que se trata de aquellos que tienen una inquietud más de política juridica que de estricta técnic o que participan de una concepción más filosófica del Derecho, y oponiéndolos a los "juristas puros" para quienes los conceptos juridicos y puros" para quienes los conceptos juridicos
las técnicas de aplicación e interpretación de normas ocupan una plaza preferente en el análisis $^{78}$. La finalidad de la aplicación de estas ideas en un estudio comparativo era en ese caso la justificación de la existencia de una familia juridica occidental, labor sólo realizable, según el mencionado autor, desde la primera optica. La razón de tal afirmación radica en que una aproximación funcional al objeto del estudio perm:te, en lugar de centrarse en los elementos que por su naturaleza son externos y contingentes, llegar a la "sustancia" de las normas, y que ésta coincide en lo esencial en los ordenamientos de Derecho civil y del common law ${ }^{79}$. El escueto desarrollo teórico del trabajo considerado, tal vez motivado por su objetivo y por estar inserto en un libro de homenaje, no obsta a su ponderación como precedente válido para una actitud metodológica que debe estimarse en general satisfactoria. Del mismo modo, poco importa que las conclusiones obtenidas puedan o no ser compartidas; lo que nos parece realmente relevante es el mecanismo para llegar a ellas.

Llama la atención que pese al espiritu funcional que se percibe en la obra de R. David, sus desarrollos y sus resultados queden en cierta medida impregnados de un aura de rigidez Sin embargo es sumamente destacable que sobre la huella trazada sean muchos los autores que en los últimos treinta años han hecho referencia, desde distintos puntos de vista, a un método comparativo funcional. En este orden de ideas, parece lícito escoger sin temor a equivocarse tres formulaciones principales, distinguidas por su carácter general y por la superación de la mera especulación, ya que se han aplicado a objetios concretos. Es lógico que ellas presenten notables diferencias, algunas muy resaltadas por os propios autores. Pero, con ojos imparciales y desde la perspectiva que interesa a este trabajo, el fondo es el mismo aunque algunos razonamientos y algunos resultados varien de una a otra concepción. Dicho fondo se configura mediante un análisis complejo de variables escogidas por mor de su significación fundamental para los ordenamientos tratados, huyendo de la atadura al Derecho positivo. Paradójicamente, el método así entendido habrá de situarse más allá de los cauces inicialmente propuestos, llegando a poner en duda la noción de comparabilidad como requisito indispensable para la labor comparativa y, por extensión, la solvencia y el interés de las clasificaciones.

20. Ahora bien, ¿en qué consisten, resumida y concretamente, las formulaciones mencionadas? En primer lugar, la que se erige como más representativa es la Stit-Doktrin fleor estilo) que propone $\mathrm{K}$. Zweigert al establecer la consideración de nuevos parámetros en vistas a la clasificación de los ordenamientos jurídicos en familias ${ }^{80}$, tarea que se dirige exclusivamente al Derecho privado. En ella se parte de la idea de que éstas están conformadas por los ordenamientos que presentan una unidad de estilo, y por lo tanto la clave consiste en identificar y tificar los elementos que pueden considerarse esenciales en la determinación del mismo. Sin desconocer que la lista de dichos elementos es variable de acuerdo con el interés de la comparación y las concepciones de quien compara, la propuesta estaria integrada por: los datos otorgados por la tradición jurídica y su evolución, la particular forma de pensar de los juristas, la presencia de
instituciones caracteristicas, el rol de las disinstituciones caracteristicas, el rol de las dis-
tintas fuentes del Derecho y su interpretación $\mathrm{y}$, en definitiva, el sustrato ideológico que informa a cada ordenamiento. Con estos elementos el trabajo concluye con una discutible división del universo juridico privado en ocho familias del universo jurico privado en

La doble limitación, material y geográfica, no parece tener mucho sentido en una argumentación dirigida exclusivamente a sostener unos criterios determinados para agrupar los orde- namientos ${ }^{82}$. Por el contrario, si el objetivo mediato de la comparación fuera otro, tal limitacion resultaria en muchos casos imprescindible. En tal caso, la mesocomparación, que en el trabajo en estudio sólo es tratada en el primer nivel, apareceria a nuestro entender como más útil, siempre y cuando se respetaran las referencias macrocomparativas a que hemos aludido. Aunque pueda parecer extraño, el dato más relevante de esta teoria no estriba en la clasificacion lograda sino en su metodologiga, basada en on lograda sino en su metodologiga, basada en una apreciación compleja que bucea más allá
del Derecho positivo, prestando especial atención a las soluciones concretas que se generan en un ordenamiento determinado.

En una oposición más aparente que real, más rimbombante que profunda, L.-J. Constantinesco ensaya también una teorización del método comparativo dirigida expresamente a la clasificación de los ordenamientos juridicos, a partir de la caracterización de los elementos "determinantes" y "fungibles" que se encuentran en el seno de cada uno de ellos ${ }^{83}$. La presencia de los elementos determinantes configurdos del mismo modo implica la existencia de un "sistema" juridico y la diferente articulación de los elementos fungibles permite la identificación de diferentes "familias" dentro de cada sistema ${ }^{84}$. Coincidiendo com lo que venimos de afirmar y en contra del propio autor, ni el hecho de la clasificación ni los resultados que se pudieran alcanzar en ese terren $0^{85}$, revisten la trascendencia que alcanza la comprensión dinámica y compleja del método comparativo.

Esta se manifesta a través de la consideracion de diversos componentes de un ordenamiento en tanto que caracteristicos (esenciales), susceptibles de servir como pautas en cualquier estudio comparativo. La lista de elementos determinantes propuesta por L.-J. Constantinesco se extiende a los siguientes: estructura, función y finalidad del Derecho; sustrato ideológico; relaciones entre la sociedad y el ordenamiento juridico; estructura econômica; papel del Estado en la organización social; situación juridica del individuo; jerarquia de las fuentes del Derecho; papel del juez en la interpretación del Derecho; forma de pensar juridicamente. Como ya hemos puesto de relieve, el catálogo expuesto no parece diferir, en terminos funcionales $y$ desde la perspectiva de nuestro análisis, de los datos subrayados por la teoria del estilo.

La tercer formulación que consideramos destacable se debe a J. H. Merryman y se diferencia de las anteriores por el hecho de no haberse planteado con el objetivo de plasmar una clasificación de familias juridicas ${ }^{86}$, sino con la idea de construir un mecanismo ágil y riguroso para hacer funcionar el método comparativo en estudios juridicos aplicados. En ella se busca una descrpción completa del ordenamiento que pare de una consideración externa (el "para si") del mismo, basada en tres dimensiones que interactúan: extensión jurídica (presencia del Derecho en la vida social), penetración juridica (referida al carácter monolegislativo del ordenamiento) y cultura juridica (modo de pensar juridicamente) ${ }^{87}$. Tales dimensiones juegan como parametros macrocomparativos que brindan una información contextual a quien compara, con la cual se puede entrar a analizar el ordenamiento "en si", compuesto por instituciones juridicas, actores jurídicos, procesos juridicos y recursos utilizados (inversión en lo juridico).

Cada uno de estos elementos, a su vez, puede analizarse mediante unas pautas concretas: legislativa, administrativa, judicial, particular, ejecución de la ley y educación y profesiones juridicas ${ }^{88}$, a fin de lograr una visión detallada y precisa en cualquier grado de la comparación. J. H. Merryman hace suya la distinción entre normas primarias y secundarias de H. L. Hart ${ }^{89}$, para llegar lógicamente a la conclusión de que el sólo estudio de las primeras da lugar a respuestas parciales y a menudo contradictorias con el "estilo" del ordenamiento. El mayor mérito de este trabajo radica en haber alcanzado matizadas aplicaciones prácticas, con lo cual el método cientifico "ácerca" del Derecho comparado que acabamos de resumir ha pasado con éxito la prueba de convertirse en un útil trabajo "de" Derecho comparado ${ }^{90}$, algo más interesante que una clasificación

\section{Método Comparativo Funcional,}

Clasificación de Familias Jurídicas y

"Derecho Latinoamericano"

21. La brevisima sintesis de las teorias anteriores no es un obstáculo para ver confirma- 
das las afirmaciones que vertiamos antes de exponerlas. Antes bien, se colige fácilmente que el propósito común de estos trabajos consiste en buscar el mecanismo que permita alcanzar resultados más rigurosos, más cercanos a la realidad que intentan descifrar. De otro lado, también se observa que se dirigen hacia objetivos más interesantes y que pueden brindar mayores resultados prácticos a los estudios micro y mesocomparativos. La macrocomparación aislada, la comparación que tiene por único objeto dos, varios o todos los ordenamientos jurijeto dos, varios o todos los ordenamientos juri-
dicos integramente considerados, cae en cambio en entredicho. Si se repara en el dato nada baladi de la influencia directa que ejerce la finalidadd concreta, en el objetivo singular, de un estudio comparativo sobre la configuración del método e incluso sobre los resultados que cabe esperar, la propia concepción del análisis funcional despliega una sombra de dudas sobre el problema de la comparabilidade ${ }^{91}$ y hace tambalear la justificación misma de las clasificaciones.

No hay más que dirigirse al ámbito espacial especifico que nos ocupa para percibir las limitaciones prácticas de aquellas construcciones teóricas que deambulan en zonas no acotadas del pensamiento juridoc. En efecto, ¿qué sucede con el "Derecho latinoamericano" cuando es pasado por los filtros del método comparativo funcional? Hemos visto como desde diferentes perspectivas más 0 menos trabajadas se han buscado razones valederas para afirmar la existencia de una familia juridica latinoamericana con rasgos de autonomia. Sin embargo, en las tesis funcionales señaladas, no se avanza especialmente sobre esta particularidad.

Si se observan las sucesivas aportaciones de K. Zweigert, es fácil apreciar la olimpica ignorancia de este sector de la realidad, basada en la idea no muy fundamentada de la "filiación" entre distintos ordenamientos. Según este autor, la presencia de dentro de cada familia de un "ordenamiento madre" evita el análisis - la consideración - de aquellos otros que han heredado o imitado su estilo. En alguna ocasión en que se ha referido a la "familia latina de Derecho privado", le ha descubierto la rara condición biológica de poseer dos "madres": el Derecho francés y el italiano. Luego, "le comparatiste devra et pourra souvent s'interdire une incursion ap- profondie dans les ordres juridiques de la péninsule ibérique et de l'Amérique du Sud ${ }^{* 92}$. Se podria pensar que la intención es restringir por podria pensar que la intencion es restringir por
regla general las comparaciones a los ordenamientos matrices; no obstante, el Derecho norteamericano como ordenamiento hijo del Derecho inglés, debe ser tenido en cuenta obligatoriamente en razón de la originalidad de su esti$10^{93}$. He aquí la clave: jlos ordenamientos latinoamericanos carecen de originalidad!

Los otros dos autores característicos mencionados, en cambio, parecen reservar una parcela algo diferenciada para ubicar al Derecho latinoamericano dentro del "sistema continental europeo" (L.-J. Constantinesco) o de la "tradición juridica romano-canónica o Civil Law Tradition" (H Merryman). Para el primero, el Tradilon (H. Merryman). Para el primero, el do el continente americano desde mediados del siglo XIX es un dato a tener en cuenta, y se traduce como la sintesis de tres fenómenos relevantes. En primer término, la existencia de un fondo común ibérico; segundo, la influencia del Código civil francés y más tarde de los Códigos italiano y español; por último, el sustrato politico perceptible en la utilización de los dos fenómenos anteriores para la elaboración de los Códigos propios ${ }^{94}$. Respecto del último, cabe afirmar que se trata del único que realiza una construcción desentendiéndose de la tarea clasificadora y que se ha aplicado posteriormente al concreto ambito espacial que nos ocupa. Em ambos extremos, como podremos observar, radica

22. También están imbuidas de un aura funcional algunas formulaciones generadas en Latinoamérica en torno al mismo objeto $0^{95}$. De ellas, merecen tenerse en cuenta una ya referida que aplica la teoria de los elementos determinantes ${ }^{96}$ y otra que sigue el derrotero metodológico de la teoria del estilo ${ }^{97}$. Ambas tienen en común la aplicación formal de uno de los métodos descrios a la justificación de la existencia autónoma de una rama latinoamericana dentro de la familia juridica romano-germánica: pero mientras la primera busca negar la originalidad, las caracteristicas especificas, que permitan obtener una argumentacion en tal sentido $0^{98}$, la segunda lleva un sentido diametralmente opuesto, invocando elementos que descubren una cierta diferencia de estilo en la rama indicada. En realidad, sólo se limita a mencionar un criterio distintivo como "ejemplo típico": el rachazo de la nacionalidad como factor de conexión personal en el $D$. I. Pr. latinoamericano, y la consiguiente preferencia por la conexión domiciliar ${ }^{99}$. A partir de esa simple mención, que se utiliza para argumentar la diferenciación entre una familia latinoamericana y la familia de los Derechos europeos de marcada influencia en América Latina (España, Portugal, Italia y Francia) ${ }^{100}$, la autora plantea una clasificación donde conviven junto a las familias consideradas, la germano-escandinava, la del common law y la socialista. Según ella estas cinco familias constituyen, desde una perspectiva latinoamericana, la primera etapa comparatista que, en el plano estricto del Derecho privado, debe limitarse a las cuatro primeras $^{101}$.

\section{IV - A MODO DE CONCLUSIONES}

23. Cuando analizamos las formulaciones basadas en criterios estáticos o aislados pusimos de relieve que no obstante la parcialidad de las mismas alguna de ellas, concretametne la que se funda en el dato de la influencia jurídica directa, demostraba con rigurosidad la proxmidad que desde una perspectiva histórica existe entre los ordenamientos espanol e iberoamericanos en el sector del Derecho privado, reclamando una lugar diferenciado para la familia juridica iberoamericana en su comprensió amplia. El último trabajo expuesto, en cambio con una metodologia dinámica aunque mucho más reducida en su fundamentación, va hacia una concepción diferente del mismo objeto (más restringida en lo espacial y más amplia en 10 material) y presenta unas aristas no circunscritas al hecho histórico, con una cierta vocación de actualidad.

Sin embargo, ninguno de los autores preten de ir más allá de un análisis macrocomparativo o, si acaso, mesocomparativo de primer nivel (limitado al Derecho privado). Pero ¿qué pasa si se busca pasar de un conocimiento cultural de innegable valor, es cierto - a una aplicación concreta del mismo? Dicho de otro modo, ¿de qué nos sirve concluir que la familia juridica latinoamericana o iberoamericana amplia o restrigida, tiene determinados rasgos caracterist cos que le imprimen un perfil diferenciado res- pecto del resto de los ordenamientos pertenecientes al tronco común romano-germánico? Para hallar respuestas válidas es preciso insistir una vez más sobre la importancia de no perder de vista el condicionamiento impuesto por el objetivo perseguido en cada tipo de estudio comparativo.

$\mathrm{Si}$ éste se desenvuelve en un ámbito macrocomparativo y se dirige a obtener una clasificación de las familias juridicas que coexisten en el mundo, su justificación dependerá de la finalidad a la cual se pretende aplicar la misma. $\mathrm{Pa}$ rece insostenible, más allá de la profundidad que puede revestir el análisis que se efectúe, que la clasificación sea considerada como un fin en si misma, y en todo caso los frutos prácticos de en el árbol de la especulación cientifica. En este sentido no creemos que la clasificación pueda erigirse en el objeto y, menos aún, en el argumento único e irrefutable de la existencia de una ciencia de los Derechos comparados, como rama autónoma de la ciencia juridica ${ }^{102}$

Es indudable que, al menos formalmente, una ciencia cuyo objeto sea la clasificación de los ordenamientos juridicos cabe en la definicion lata "(sector de un) cuerpo de doctrina metódicamente formado y ordenado, que constituye un ramo particular del humano saber". Pero tambien lo es que una construcción de este tipo sólo sería un consuelo para quienes quieren fundar una ciencia a toda costa, habida cuenta de su pobreza y de sus limitaciones, a la par que confaiere razón a aquellos que califican a esta actividad cientifica que empieza y termina en la clasificación, de "meras piruetas del intelecto o de la curiosidad cientifica" 103

En este orden de ideas, un estudio exclusivamente macrocomparativo caerá irremesiblemente bajo la guillotina de la última afirmación citada. Sin embargo, si la confrontación/comparación de los macrocomponentes de dos o más ordenamientos sólo se realiza buscando constituir un marco de referencia para la definición de un espacio micro o mesocomparativo concreto la "pirueta" intelectiva puede en algunos casos ser interesante y hasta tener resultados prácticos

24. Llegados a este punto, alguien no demasiado ducho en la lectura entre lineas podria preguntarnos: ¿y la familia juridica latinoame- 
ricana? ¿ existe o no existe? Y nosotros, haciendo gala de una actitud condescendiente, podríamos construir un excurso intentando fundamentar esa existencia a partir de ciertos rasgos originales, más en el ámbito extrajuridico que en el estrictamente juridico ${ }^{104}$. Porque, a no engañarse, la diferencia estriba no tanto en los contenidos normativos sino sobre todo en la "realidad operacional" de los mismos. Precisamente, uno de los elementos - no el único - que provoca la "disfunción" entre los textos legales y su aplicación es la exagerada longevidad de aquéllos.

Pero, de todas maneras, ni el "estilo", ni los "elementos determinantes", ni la "extensión", la "penetración" o la "cultura" jurídicas, llevarian a la identificación clara de una familia juridica latinoamericana o iberoamericana amplia que, alcanzando un grado de coherencia minimo, pudiera diferenciarla de otras familias. A lo máximo que se puede aspirar es a una aproximación mesocomparativa, camino no exento de dificuldades, pero que adquiere cierta relevancia en la medida en que constituya un medio para alcanzar algún tipo de unificación convencional más o menos pretensioso ${ }^{105}$. Sin embargo, hemos podido comprobar ${ }^{106}$ que asi como la pertenencia a una misma familia (si se admite tal extremo) no garantiza el éxito de ningún esfuerzo unificador, es constatable que se han logrado no pocos resultados en trabajos inter familias, dependiendo de las materias afectadas ${ }^{107}$. Es decir que, en definitiva, en el ámbito de la microcomparación la clasificación no tiene ningún sentido $\mathrm{y}$ en los niveles meso y macrocomparativos su utilidad es muy relativa. ¿Debemos toavia agregar algo más?

\section{NOTAS DE REFERÊNCIA}

1 Nos referimos a nuestros trabajos "L'influence des conventions internationales sur l'actualisation du en Permeabilite des ordres juridiques. Rapports pre en Permeabulle des ordes lundihtes. Rapports presentés à locassion du colloque-anniversaire de linstitut sǘn castellana enriquecida en Ju2, pp. 217-234 (verna (Buenos Aires), núm. 5585 (1993) 2-14) y La cona (Buenos Aires), num. 5585 (1993) 2-14) y La coca Latina, Madrid 1994 (en prensa). A elos remitica La tara, Ma precisión de los términos " lom remitidica" y "latinoamericana", respectivamente.
2 En realidad, también resulta muy dificil agrupar con cierta rigurosidad no ya ordenamientos sino sistemas o subsistemas concretos, como hemos puesto de relieve respecto del Derecho internacional privado.

Vid., por todos, Malmström, A., "The System of Legal System. Notes on a Problem of Classification in Comparative Law", en Scandinavian Studies in Law (Estocolmo), 13 (1969) 127-149.

4 En este sentido, se han clásificado los criterios de clasificación (valga la redundancia) en: naturalesetnológicos, culturales, legislativos y juridico-genéticos. Cf. Martinez Paz, E., Introducción al estudio de Derecho civil comparado, reimp., Buenos Aires 1960 p. 152. A su turno, Constantinesco, L.-J., Traité de droit comparé, Paris 1983, t. III, pp. 93 ss., se lim

5 Cf. Martinez Paz, E., o. c., pp. 152-153 y Arminjon P., Nolde, B., y Wolff, M., Traité de droit comparé, Paris 1950, t. I., p. 42.

6 Esmein, A. "Le droit compare et l'enseignement du droit comparé", en Congrès international de droit com paré Procés verbaux Paris 1900 t I pp. $445 \mathrm{ss}$. 7 Bryce, J., Studies in History and Jurisprudence, Oxford 1901 , t. II, p. 189, citado por Constantinesco, L.-J. o. c., pp. $95-96$

8 Taylor, The science of jurisprudence, Nueva York 1903 p. 42, citado por Constantinesco, L.-J., o. c., pp. 95-96.

Esta clasificación se debe a Sauser-Hall, G., Fonction et méthode du droit comparé, Ginebra 1913, pp. 101 ss., y sucumbió, afortunadamente, a la autocritica, aunque demasiados años despues. Idem. "Prólogo", en Recueil de travaux suisses présentés au IVe Congrès international du droit comparé, Ginebra 1959, p. XIII.

10 Es el criterio tomado por de Sola Cañizares, F., Iniciación al Derecho comparado, Barcelona 1954, pp. 169 ss., aunque él habla del "espiritu común" de los derechos agrupados en cada familia. La religión tambien se muestra como la base de la clasificación aceptada por von Fikntscher, W., Methoden des 1977 y recho comparado y los sistemas juridicos conteme De recho comparado y los sistemas juridicos contemporá neos, Lima 1991, pp. 148-149. Para una crítica (T) Rech6.

11 El Derecho chino se cae del cuadro debido, según el primer autor señalado en la nota anterior, sus fundamentos filosóficos y morales, su carácter esencialmente consuetudinario y su "sovietizaciónn". Obviamente, muchas de estas consdieraciones carecen, al menos, de actualidad.

12 Eichler, H., "Die Rechtskreise der Erde", en Estudi os de Derecho civil en honor del Prof. Castán Tobeñas Pamplona 1969, pp. 294 ss. Idem, Gesetz und Sys tem, Berlin 1970, pp. 66 ss.
13 En estudios posteriores, Eichler afirma la existencia de caracteres originales en el Derecho latinoamericano. Vid. Eichler, H., "Codificación de Derecho civil y teoria de los sistemas de Derecho (algunas consideraciones acerca de un futuro sistema del Derecho civill", Revista da Facultade de Direito (San Pablo), 68-2 (1973) 229-256, y "Privatrecht in Lateinamerika", Osterreichs Rechtsleben in Geschichte und Gegenwart, Berlin 1981, pp. 481-507.

4 David, R. y Jauffret-Spinosi C., Les grands systè mes de droits contemporains, Paris, 1988, pp. $21-23$

5 David, R., Tratado elemental de Derecho civil comparado, trad., Madrid 1953, pp. 205 ss.

6 Idem, ibid. El último dato se incluye como elemento esencial en Idem, "Existe-t-il un droit occidental?" en XXth Century Comparative and Conflicts Law. Le gal essays in hono rolica a las criticas que habin suscitado sus a firmaciones en el Tratado. La misma explicación se reproduce sintéticamente en FRAMONT, M., Les grands systèmes de droit contemporains, Paris 1987, p. 5.

17 David, R. y Jauffret-Spinosi, C., o. c.

8 Aqui aparecen órdenes tan disimiles como el mulsumán, el hindú, el hebreo, el canónico (?) los derechos del Lejano Oriente y los del Africa negra Madagascar. Con más rigor, en las ültimas ediciones de la versión francesa de Les grands systèmes... o. c. habla de "otras concepciones del orden social del Derecho". Vid. también la Introducción al vol. II. cap. 1 de la Int. Enc. Comp. Law., 1972, publicado como "Les differentes conceptions de l'ordre socia et du droit, en Le droll compare. Drolls d hier, droils de demain, París 1982, pp. 93-108. En contra de tratamiento "residual" de ciertos ordenamientos, Reyntjens, F., "Note sur l'utilité d'introduire un système juridique "pluraliste' dans la macro-comparason des droits", en Revue de droit international et droit
comparé (Bruselas), (1991) 41-42.

Como veremos, en "Loriginalité des droits de IAmérique latine", en Le droit comparé..., o. c.., pp. 161-173, R. David afrma en forma matizada esta cualidad. En Espana esta clasillcacion es seguida por J. Castín Tobenas, quien dentro de la famila romano-cristiana destaca la existencia de un grupo latino donde se situan los Derechos francés, italiano e ibérico. Vid Castan Tobeñas, J. Los sistemas juricicos conlemporineos del mundo occidenmas juridicos contemporaneos del mundo occidenal, Madrid 1956, p. 23 Bevilaqua, C., sin enbargo, lo introduciria en esta liçōes de legislação comparada sobre o direito privado. Bahia, ${ }^{2} 1897$.

22 Vid. Arminjon, P., Nolde, B. y Wolff, M., op. cit., t. p. 45. El dato histórico, "des rapports de derivation et de ressemblance", se demuestra como el más importante, pese a que los autores senalen su preo- cupación por el contenido de los derechos privados considerados. En el mismo sentido, Constantinesco, L.-J., o. c., pp. 108-112 y Zweigert, K. y Kötz ., Introduction to Comparative Law, trad., Oxford, 1992, pp. 69-70. En contra, de Maekelt, T. B., "Relexiones sobre Derecho Comparado, Libro homenaje a la memoria de Joaquin Sánchez Covisa, Caracas 1975 , p. 225

3 Grisoli, A. Corso de diritto comparato, Milán 1962, p. 71 y Constantinesco, L.-J., l. c. nota anterior.

Es el criterio seguido por Sarfatti, M., Introduzione allo studio del diritto comparato, Turin 1933, pp. 51 ss. y Rodiere, $R$.
ris pp. $31-32$.

Cabe mencionar, además, que la visión que los juistas del common law tienen acerca de la codficacjarse Vid. Bodenheimer E "Is Codification an Outmoded Form of Legislation", American Journal of Comarative Law, 30 Supp. (1982) 15-29.

26 Vid. Catalano, P "Sistemas juridicos. Sistema juri dico latino-americano y Derecho romano", en Revis ta General de Legislación y Jurisprudencia, 131 (1982 173 ss. - para un breve "anticipo" de sus ideas, cf. dem "Derecho romano y paises latinoamericanos", en la misma Revista, 128 (1979) 637-640-, y Schipani, S., "Nota introduttiva" $Y$ "Dal diritto romano alle codificazioni latinoamericane: l'opera di A. Teixeira de Freitas", en Studi Sassaresi, vol. V, Milan 1981, pp. VII-XXXV y 589-607, respectivamente. La influencia del Derecho romano sobre las codificaciones latinoamericanas es un tema recurrente. Vid recientemente, Iglesias, R. y Morineau, M., "La influencia del Derecho romano en el Derecho civil mexicano: los códigos civiles de 1870, 1884 y 1928, de Derecho Privado (México, D. F.), (1992) $51-63$

Vid. de los Mozos, J. L., "Perspectivas y método para la comparación juridica en relación con el Derecho privado lberoamericano", en Revista de Derecho Prvado, 60 (1976) 775. Tam suen les systèmes juridiques

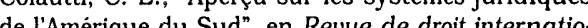

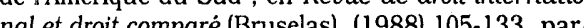
ten de los códigos, aunque en un trabajo que incorpora elementos de Derecho püblico.

28 "Les codes sont une chose et Droten est une autre, ro sobre esta misma cuestión vid, R., "Loriginalité...", l. c.. p. 162

29 Bevilaqua, C., op. cit.. pp. 73 ss.

30 Constantinesco. L..J., o. c. p. 102 , hace hincapié en estos extremos para calificar como artificial el cuarto grupo agregado por $C$. Bevilaqua.

31 Vid. Martinez Paz, E., o. c., pp. 155 ss.

32 Se trata, por supuesto, del trabajo de David, $\mathrm{R}$. "Loriginalité...", l. c.. Compárese la conclusión fundamental del mismo (p. 172) con los argumentos antes expuestos. No se nos escapa que este articulo fue escrito en $1953 \mathrm{y}$ que puede pensarse en alguna 
variación posterior en el pensamiento de su autor. Sin embargo, él mismo desvanece esta objeción en el Preface a Le droit comparé..., o. c., p. 8.

33 Lo que F. Schmidt denomina método "multi-axial", en "The Need for a Multi-Axial Method in Comparative Law", en Festschrift für Konrad Zweigert, Tubinga 1981, pp. 525-536.

34 Por ejemplo, resulta muy imprecisa la referencia a la unidad de tradición y de ideal.

5 Para la matización de esta influencia, a nuestro juicio ostensible, cf. Villela, A.M., "Direito romano e sistema juridico latino-americano", Revista de Informaçāo Legislativa (Brasilia), (1981) 115-124. Vid. sin embargo, el revelador análisis de Castan Vazquez, J. M! , en La influencia de la literatura juridica española en las codificaciones americanas, Madrid 1984, pp. 64 ss., quien, contraponiendo "los rápidos cambios en el Derecho público" a "la permanencia del Derecho privado", transciende ampliamente la tesis de

36 Para David, R., "L'originalité...", L. c., p. 169, resulta paradójico que este aspecto de la originalidad proet de l'universalisme mesmedéles que les ont inspirés,

7 Idem Ibid p. 171. No obstante, la idea segin la cual la originalidad de los ordenamientos de Latinoamérica no es distinta a la de los otros que conforman la misma familia, es recogida a pies juntillas en Rodriguez Ramos, M., "Visión de conjunto del Derecho de América Latina", en Revista General de Legislación y Jurisprudencia, (1960) 7-27.

38 Vid., principalmente, de este autor, "El sistema de Derecho privado iberoamericano", en Estudios de Derecho civil en honor del profesor Castán Tobeñas, $o$. c., pp. 155-188. Cf. la repercusión de estas ideas en H. Eichler (supra, nota 13), de los Mozos, J. L., "Algunos aspectos de la influencia hispánica en el Có-
digo Civil de Andrés Bello", en Revista General de Legislación y Jurisprudencia, (1978) 437-467, Moisset de Espanes, L., "Derecho civil español y americano. Sus influencias reciprocas", Revista de Derecho Privado, 56 (1972) 599-614, Idem, "La codificación española y su influencia en el Código civil argentino", Anuario de Derecho Civil, 43 (1990) 713735 y Baro Pazos, J., La codificación del Derecho civil en España (1808-1889), Santander 1993, pp. 151-

99 Vid. Castan Vazquez, J. Mª, La influencia..., o. c., pp.

40 En su discurso de contestación al de J. Ma Castán Vázquez en la recepción pública de éste en la Rea Academla de Jurisprudencia y legislacion, A. Heren lo politico $y$ ans instituciose de Derecho pien lo politico y en las instituciones de Derecho pula lengua y el derecho privado, que son dos medios de comunicación entre las persons, sin un propo- sito preconcebido, se alcanzó la unidad". La influencia..., o. c., pp. 182-183.

Vid. de Castro y Bravo, F., "La doble nacionalidad" Revista española de Derecho internacional. I (1948) 104, y ponencia del mismo titulo en Actas del Primer Congreso Hispano-Luso-Americano de Derecho Internacional, Madrid 1952, p. 361. Cf. Castan Vazquez, J. $M^{\mathrm{a}}$, "La comunidad iberoamericana en el pensamiento de Frederico de Castro", Anuario de Derecho civil, 36 (1983) 1217-1225. 43 Vid., especialmente, las obras de P. Catalano y $\mathrm{S}$.
Schipani, citadas supra en nota 26 .

C. Fernandez Sessarego, por ejemplo, basa toda su argumentación sólo en el análisis - bastante superficial, por cierto - de los origenes de algunos códigos latinoamericanos. Vid. "Comparación juridica y unidades del sistema jurídico latinoamericano", Revista de Derecho y Ciencias Politicas (Lima) Villela A $M$. 1 .

lilela, A. M., l. c., utiliza una metodologia más rea-

P. Catano y S. Schiponit continesco.

. Catalano y S. Schipani, con algunas diferencias, P. Custan esta postura teniendo en cuenta, precisaEuropa relativa pureza que se le descubre en América.

47 Es el caso de A. M. Villela y C. Fernández Sessarego. Vid., sobre esta idea, Zajtay, I.. "La permanence des concepts du droit romain dans les systèmes juridiques continentaux", Revue international de droit comparé (Paris), (1966) 353-363.

48 Esto es casi imposible de diferenciar en Estados Unidos, por ejemplo. Vid. Garro, A. M., "Shaping the Content of a Basic Course on Latin American 590

49 Cf. Castan Vazquez, J. Ma , La influencia..., o. c., pp. 77-82 y Pescatore, P., Introduction à la Science du droit, Luxemburgo 1960, pp. 60-6

Merryman, J. H., "Modernización de la ciencia juridica comparada", en Boletín mexicano de Derecho comparado, (1983) pp. 71-72 y 84. Un adelanto parcia de las ideas aqui expuestas se observa en Idem, "Fines, objeto y método del Derecho comparado", en e mismo Boletin, (1976) 65-92. Fix-Zamudio, H., "John Henry Merryman and the Modernization of Coma-

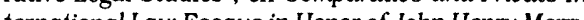
ten on his Seveltis man on his Seventieh Brhay, Beth, 1950, pp. 2547, y Cappelletl, M., "John Henry Merryman the 1079-1086, che stanjord Law Revieu, 39 (1987) su influencia.

Lartación pionera de R. von Jhering a la configuración de un metodo comparativo critico, no dog- gert, K. y Siehr, K., "Jhering's Influence on the Development of Comparative Legal Method", en American Journal of Comparative Law, 19 (1971) 215-231.

52 Es lo que M. Ancel llama "realidad operacional" de un ordenamiento, en un contexto en el cual acentúa la importancia de la función social de cualquier institución sobre su definición o caracterización juridica. Vid. "Le problème de la comparabilite et la méthode fonctionelle en droit comparè, en Mélanges

en l'honneur d Imre Zajtay, Tubinga 1982, pp. 1 -6

53 Vid. la autorizada opinión de N. Bobbio en el Prólo go a la edición castellana de su Teoria general del Derecho, Madrid, 1991, pp. 9-10 y, con más ampltud, en idem, "El análisis funcional del Derecho: tendencias y problemas", en Contribución a la teoria de

54 Vid. Rozmaryn, S., "Les grandes controverses du droit compare, , Inchieste di diritto comparato, Milán-

Nueva York 1973, t. Il, pp. 580-582.

Resiltan valldas en este sengu- muchas de las criticas que $\mathrm{H}$. Dolle dinge a $\mathrm{K}$. Zweigert en "Rechts(1970) 403-410

56 Esta explicacioon matizadora se encuentra en Kötz, H., "Rechtsvergleichung und Rechtsdogmatik", en RabelsZ, 54 (1990) 203-216, respecto a la comprensión que habia alcanzado la idea de un funktionelle und antidogmatische Methode con

57 Merryman, J. H., "Modernización...", l. c., pp. 8384.

58 Idem, Ibid., pp. 73 ss.

59 No obstante, J. H. Merryman se ha destacado en la aplicación práctica del método comparativo con la realización de investigaciones sumamente útiles sobre este campo. Vid., Idem. The Civil Law Traditon. An Introduction to the Legal Systems of Western Europe and Latin American, Stanjord, ${ }^{2}$ 1985, e idem Clark, D. S., Comparative Law: Western Europea and Latin American Legal Systems. Cases and Mater als, Indianápolis, 1978

60 Merryman, J. H., "Modernización...", l. c., esp. 73 77.

61 Idem, Ibid., p. 8

Blagojevic, B., "La méthode comparative juridique", en inchieste de diritto comparato, o. c.. p. 22

Vid. Gutteridge, H. C., Droit comparé, trad. Paris, 1953, pp. 102-103, Langrod, G., 'Quelques reflexons ind ce juridique", en Revue international de droit compare du droit comparé", Mélanges offerts à J. Maury, Paris 1960 , t. I., p. 507.

64 Vid. Grzybowski, S. "Le but des recherches et les méthodes des travaux sur le droit comparé", Inchieste de diritto comparato o. c. 332 . Logicamente. la finalidad perseguida define el objeto de la comparación.

65 Vid, en esta linea, la opinión de David, R., Tratado..., o. c., p. 27. 66 Vid.. Constantinesco, L.-J., o. c., pp. 284-285, en-
sayando una refutación de H. C. Gutteridge y R. David.

67 Gutteridge, H. C., o. c., p. 104.

Es lo que en cierta manera propugna Ancel, M., en "Quelques considerations sur les buts et les méthodes de la recherche juridique comparative", en In chieste de diritto comparato, o. c., pp. 9-10.

69 Vid. Ascarelli, T., "Función del Derecho comparado en la interpretación del Derecho y metodologia del Derecho Comparado", Revista del Instituto de Dererecho Comparado Barcelona), 1 (1953) 26, para quien dicha fungibilidad guarda relación con las diferentes condiciones "ambientales" en las cuales se desarrollan las instuciones. C.., asimismo, Zweigert, tes. paè", pare6) 5-18, Constantinesco, L J o o. c. t. II. pp. 81-86 y Rigaux . F. "Science comparative et droit positif", en Festschrift für Karl $H$. Neumayer zun 65. gositir, en Festschrijt

70 Es conocida al respecto la frase de $F$. Lawson: "even the most complete and most logical system of law is not perfectly intelligible until it is viewed in relation to other legal systems". Vid. "The Field of Comparative Law", en The Comparison, Selected Essays, Amsterdam 1977, t. II, p. 3

71 Vid. Zweigert, K. y Kotz, H., o. c., pp. 29 ss.

72 De Maekelt, T. B., l. c., pp. 219-222, utiliza el ejemplo de la extensión practica de las causales de nuldad del matrimonio con las cuales se integraba la carencia normológica de aquéllos ordenamientos que no consagraban el divorclo vincular

3 Para una critica a esta actitud, vid. Kramer, E., "Topik und Rechtsvergleichung", en RabelsZ, 33 (1969) 9 ss. Vid. tambien Neumayer, K. H., "Fremdes Recht aus Büchern, fremde Rechtswirklichkeit und die funktionelle Dimension in den Methoden der Rechtsvergleichung", en RabelsZ, 34 (1970) 411-426, quien brinda elementos para la necesaria apreciación de Decho en acclon (Rechestatsachen. Un catalogo de ejemplos de los errores más comunes en que lo laro de la obra de David $R$. Tratado o.

4 Merryman, J. $\mathrm{H}$."Modernización..." l...., pp. 77

78 y Ancel, M "Le probléme de la comparabilité. c.. p. 6.

75 Valsa como ejemplo el señalado por Rabel, E., "Tarea y necesidad del Derecho comparado", en Revista del Instituto de Derecho comparado de Córdoba (Argentina), (1947) 109: "los más perfectos derechos del inquilino, según el Código Civil alemán, no tuvieron en la práctica ningun efecto en virtud de los famosos formularios de los proprietarios de casas'. 76 Zweigert, K., define al Derecho comparado básicamente como una confrontación, ya sea entre orde-

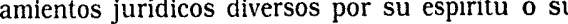
estilo, ya entre instituciones o soluciones compara- 
thodologie..." l. c.). En cualquier caso, parece dificil $y$ desaconsejable el divorcio de ambos aspectos de la confrontación.

77 Vid., especialmente, Drobnig, U., "Methods of Sociological Research in Comparative Law", en RabelsZ, 35 (1971) 496-504. Para elementos de una relación entre Derecho comparado y Sociologia del Derecho, vid. Idem. "Rechtsvergleichung und Rechtssoziologie", en RabelsZ, 18 (1953) 295-309.

78 Señala R. David que utiliza la palabra "funcional", por tratarse de una expresión "à la mode". Vid. "Existe-t-il un droit occidental?", l. c., p. 58

79 Para R. David esa caracteristica esencial que distingue al Derecho occidental es la "rule of law", el ideal según en cual la sociedad debe estar regida totalmente por el Derecho. Idem, Ibid., pp. 59-60.

Esta teoria vio la luz en el trabajo "Zur Lehre von den Rechtskreisen", en XXth Century Comparative and Conflicts Law. Legal essays in hon of llessel Ynteón en Zweigert, K. y Kötz. H., o. c., pp. 63-75.

81 Romanista, alemana, nórdica, del common law, so cialista, asiática. hindú e islámica.

82 Para uma critica concienzuda sobre ambos extremos $c f$. la reseña de David, $R$. Revue international de droit comparé, (1972) 516-519. Preñadas de subjetivismo la mayor parte de las ácidas criticas de Constantinesco, L.-J., o. c., t. III, pp. 127-136 y 155157 , no merecen atención por mor de su inconsistencia.

83 Vid. Constantinesco, L.-J., o. c., t. III, pp. 164 ss., esp. 227-235. Las bases de esta teoria se fundan en su concepción acerca del método comparativo desarrollada en el t. ll de la obra citada.

84 Asi, dentro del sistema continental europeo, el autor diferencia cuatro familias: romanista, latinoamericana, nordica y germanica, y dentro del sistema angloamericano, las familias ding mericana. Idem, Ibid., pp. 84-85.

85 Téngase en cuenta que L.-J. Constantinesco tenia prevista la publicación de un cuarto tomo del Tratado destinado a la clasificación de los sistemas jurídicos, es decil "al objeto de la ciencia de los derechos comparados, pero falleció poco antes de termin in tero. Por esta raton, sus conclusiones bajos, desconociendo cualquier evolución posterior. or.

Aunque, en otro trabajo (The Civil Law Tradition... o. c., pp. 1-5) su autor haya afirmado la existencia demano-canónica y socialista.
romes 7 Merryman, J. H “Modernizaio

Ss.
Idem, Ibid., pp. 80-81.

89 Vid. El concepto de Derecho, trad., Buenos Aires 1963. 90 Merryman, J. H., "Modernizacion...", I. c., pp. 72

$91 \mathrm{Cf}$. Ancel, M., "Le problème de la comparabilité...", l. c., p. 5. Sin embargo, según Zajtay, I., "Réflexi- ons sur l'evolution du droit comparé", en Festsclirift für Konrad Zweigert, Tubinga 1981, pp. 595. $601)$, la clasificación es indispensable y determina el grado de comparabilidad, ;incluso en estudios microcomparativos! La misma idea podia inferirse ya de Idem, "Réflexions sur le problème de la division des familles de droit", en RabelsZ, 37 1973) $210-216$.

92 Zweigert. K., "Méthodologie...", l. c., p. 585.

Idem. Ibid. El autor es tajante: "le comparatiste qui .

95 También parece seguir esta tende. 113. de de los MOZOS, J. L., "Perspectivas...", l. c., que reclama una atención prioritaria del "sistema interno" como objeto del método comparativo.

96 Vid. Villela, A. M., l. c., pp. 119 ss.

97 Vid. de Maekelt, T. B., l. c., pp. 227-228.

Después de revisar escuetamente cómo se configuran los elementos determinantes del Derecho latinoamericano, Villella, A. M., l. c., concluye que juridicamente, pelo menos, a America Latina faz bloco unico com a Europa".

9id. de Maekelt, $T$. B., l.c. una optica eminentemente iusprivatista.

01 De Maekelt, T. B., l. c

102 En contra, Constantinesco, L.-J., o. c., t. III, pp. 19-49 y 75-78, para quien constituye el centro de su argumentación (también en Tratado de Derecho comparado, trad., Madrid 1981, vol. I, pp. 309-317). Sin embargo, como puede observarse a los largo de estas reflexiones, no hemos pretendido, tampoco creemos que proceda, tratar aqui la tantas veces llevada y traida lalsa dialéctica "ciencia de los derechos comparados vs. método comparatifructiferas quente una de las discusiones menos de la Ciencia juridica.

103 Aguilar Navarro, M., Derecho internacional privado, Madrid 1976, vol. I, t. I, p. 70 . Desde hace tiempo se destaca la escasez de resultados prácticos que se obtienen mediante las clasificaciones. 04 En este sentido, vid. Segal, R., Pinto, M. y Colautti, C. E., o. c.

105 Finalidad esencial reconocida a los estudios comparativos

106 Vid. nuestros trabajos citados en nota 1.

Diversos aspectos de esta idea vienen siendo puestos en tela de juicio desde hace algún tiempo. Vid. Strömholm, S., "Rechtsvergleichung und Rechtsangleichung. Teoretische Möglichkeiten und 7. 56 (1992) 611-622. Incluso se ha dicho que referirse a la "armonizacion" del Derecho en el seno de una familia juridica, implica en cierto modo una tautologia ya que "families of law constitute systems which include a harmonization component by definition". Vid. Boodman, M., "The Myth of Harmonization of Laws", en American Journal of Comparalive Law, 39 (1991) 704.

\title{
A Remissão no Direito Tributário Brasileiro
}

\author{
EuRÍPEDES GOMES FAIM FILHO \\ Juiz de Direito no Estado de São Paulo. \\ Ex-professor de Direito da UNESP, ITE e UNOESTE. \\ Membro do IBDT/USP \\ Pós-graduando da Faculdade de Direito \\ do Largo de São Francisco da USP
}

\section{INTRODUÇ̃̃O}

Encontramos pouca literatura juridica sobre o tema remissão tributária a maioria dos livros e tratados apresenta breve estudo sobre o assunto, às vezes resumido a uma única página, por isso entendemos que é necessário discorrer mais sobre este tema dando-lhe um tratamento mais profundo e foi o que tentamos fazer aqui e isto também porque achamos que a remissão tem sido usada como errado instrumento de politica fiscal, como exporemos no texto.

Assim, tentaremos neste trabalho dizer o que se pode entender como sendo remissão, qual sua natureza juridica e requisitos legais, bem como outras observaçōes sobre o assunto, sem ter a pretensão de esgotá-lo.

Por fim, analisaremos um exemplo concreto de lei que tenha concedido este beneficio fiscal para averiguar se os requisitos legais têm ou não sido seguidos.

Desta forma pretendemos dar uma pequena contribuição sobre o assunto que achamos de grande relevância pelos motivos que daremos no decorrer do texto.

\section{CONCEITO DE REMISSÃO}

Pode-se conceituar a remissão como sendo o ato praticado pelo credor que, por liberalidade, desobriga o devedor de quitar a divida.

$J \operatorname{ardim}^{2}$ ensina que a origem etimológica da palavra é a seguinte: re (para trás) + missio (deixar-se levar) = remissio-onis (mandar para trás, abrandamento, suavidade, indulgência e perdão).
Lembra Baleeiro ${ }^{3}$ que não se pode confundir remissão com remição, que antigamente tinha a mesma grafia causando maior confusão do que hoje. Explica ele que remição vem do latim redimere ato de remir, redimir ou resgatar a divida por parte do devedor ou algum interessado 4 .

Já remissão tem sua origem na palavra latina remissio, remissionem, ato de remitir, em outras palavras, perdoar a divida, renúncia do credor ao seu crédito.

Ocorre muita confusão também com 0 instituto da anistia fiscal, o que não deveria acontecer porque esta abrange exclusivamente as infrações cometidas ${ }^{5}$ enquanto que a remissão não trata de infrações, mas sim de débitos fiscais normais.

Ensina, contudo, Denari ${ }^{6}$ que na essência as noçōes de anistia e de remissão estão interligadas, pois ambas estão relacionadas ao perdão de um débito tributário, sendo a anistia espécie de remissão que se aplica às penalidades por infraçōes tributárias.

Tanto no Direito Tributário quanto no Direito Privado a remissão pertence à parte obrigacional e se trata de uma liberalidade do credor, a diferença reside no fato de que neste ela resulta da vontade das partes e naquele ela se origina na lei.

Ressalte-se que como a remissão é um ato de disposição de patrimônio o credor que a realiza necessita possuir capacidade para agir e disponibilidade do bem, o que se aplica no Direito Tributário onde apenas 0 ente com capacidade de instituir o imposto pode perdoá-lo.

Por fim, não se olvide que no Direito Privado o instituto da remissão não se confunde com a 